\title{
Evaluation of Amelotin Expression in Benign Odontogenic Tumors
}

\author{
Daiana P. Stolf ${ }^{1}$, Tae-Young Lee ${ }^{1}$, Grace Bradley ${ }^{2}$, Bernhard Ganss ${ }^{1}$
}

\author{
${ }^{1}$ Matrix Dynamics Group, Faculty of Dentistry, University of Toronto, Toronto, Ontario, Canada \\ ${ }^{2}$ Oral Pathology and Oral Medicine, Faculty of Dentistry, University of Toronto, Toronto, Ontario, Canada
}

Received: March 29, 2013

Accepted: May 06, 2013

Published Online: May 11, 2013

DOI: $10.5455 /$ jihp. 20130506045106

\section{Corresponding Author:}

Bernhard Ganss,

Matrix Dynamics Group 150 College

Street, FitzGerald Building, Room 234,

Toronto, Ontario, Canada - M5S 3E2

b.ganss@utoronto.ca

Keywords: Amelogenesis, Amelotin, Odontogenic Tumors

\begin{abstract}
Objective: Amelotin (AMTN) is highly and selectively expressed by odontogenic epithelium-derived ameloblasts throughout the maturation stage of enamel formation. The protein is secreted and concentrated at the basal lamina interface between ameloblasts and the mineralized enamel matrix. Odontogenic tumors (OT) are characterized by morphological resemblance to the developing tooth germ. OT vary from slowly expanding, encapsulated tumors to locally aggressive and destructive lesions. The purpose of this study was to determine the expression profile of AMTN in benign odontogenic tumors and to correlate it with specific features of the lesions.

Methods: Immunohistochemical staining for AMTN was performed on human ameloblastoma, ameloblastic fibroma (AF), ameloblastic fibro-odontoma (AFO), odontoma, adenomatoid odontogenic tumor (AOT) and calcifying cystic odontogenic tumor (CCOT).

Results: Generally, ameloblastoma and AF did not stain for AMTN. A strong signal was detected in ameloblast-like layers of AFO and odontoma. Epithelial cells in AOT did not stain for AMTN, while calcifying areas of extracellular eosinophilic matrix were intensely stained. Interestingly, ghost cells present in odontomas and CCOT revealed variable staining, again in association with calcification foci.

Conclusions: Amelotin expression was consistently detected in tumors presenting differentiated ameloblasts and obvious matrix deposition. Additionally, the presence of the protein in the eosinophilic matrix and small mineralized foci of AOT and calcification areas of ghost cells may suggest a role for AMTN in the control of mineralization events.
\end{abstract}

\section{INTRODUCTION}

Tooth development is a complex process that occurs through an intricate chain of interactions between tissues derived from oral epithelium and ectomesenchyme [1-4]. This developmental process ranges from initiation and morphogenesis, where the enamel organ is formed, to differentiation of key cells odontoblasts and ameloblasts - and subsequent mineralization of the matrices deposited by them [1, 57].

The organic enamel matrix is composed primarily of amelogenin (AMEL) isoforms, a group of low molecular weight proteins [1]. They account for more than $90 \%$ of total protein content, which form large self-aggregates ("nanospheres"), and are believed to control lateral growth of hydroxyapatite crystals. Other, far less abundant proteins found in the growing enamel matrix include enamelin (ENAM) and ameloblastin $(\mathrm{AMBN})$, which are believed to function as promoters for crystal elongation and adhesion molecule between ameloblasts and mineralizing enamel, respectively. During and after the secretory stage, two types of proteinases are produced by ameloblasts, which are responsible for processing and degrading the organic component of enamel: the matrix metalloproteinase family member Enamelysin (MMP-20), and the serine proteases Kallikrein 4 (KLK4). Concomitant with the 
removal of matrix proteins, hydroxyapatite crystals grow in thickness, resulting in enamel with its characteristic mineral content of over $96 \%$ [4].

Since the complex process of amelogenesis is still not completely understood, efforts in identifying components differentially expressed in various dental tissues have recently led to the discovery of Amelotin (AMTN) as a secreted ameloblast gene. AMTN shows a restricted expression pattern beginning at the transition from secretory to maturation stage ameloblasts and persisting in reduced ameloblasts until the time of tooth eruption [8]. Immunolocalization of this protein to the basal lamina interface between the ameloblast cells and the enamel matrix throughout the maturation phase was also reported [4, 9]. The characteristic expression pattern, together with the ability of AMTN to bind hydroxyapatite (unpublished) suggest a possible involvement in cell adhesion, control of calcium and protein transport into and out of the maturing enamel matrix, and/or control of matrix mineralization.

Odontogenic tumors (OT) are rare, generally benign neoplasms thought to be derived from remnants of the tooth-forming apparatus. Thus, they resemble many morphological characteristics and replicate inductive interactions that occur in normal tooth development [10]. The most widely used classification of these tumors has been structured by the World Health Organization (WHO), and is based on the types of tissue involved in the lesion $[10,11]$. According to the newest version of this classification, tumors consisting of odontogenic epithelium with mature stroma but without odontogenic ectomesenchyme include ameloblastoma and adenomatoid odontogenic tumor (AOT). Lesions such as ameloblastic fibroma (AF), ameloblastic fibro-odontoma (AFO), complex and compound odontomas and calcifying cystic odontogenic tumor (CCOT) are classified as mixed tumors, i.e., originating from odontogenic epithelium and ectomesenchyme with or without dental hard tissue formation [11].

Odontogenic tumors are usually slowly growing lesions and many are found during routine radiographic examinations. However, some present aggressive and invasive behavior and rarely, they can show malignant transformation and metastasis, as reported for cases of ameloblastoma, AF, and CCOT [6, 10, 12-19].

Previous immunohistochemical studies have detected structural enamel proteins such as amelogenin, enamelin and ameloblastin, as well as the proteinase MMP-20 in several types of OT [20-26]. Since the tumors of the odontogenic apparatus closely mimic the tissue organization and also the inductive changes that occur in the developing tooth, the study of these proteins may provide relevant information not only for morphological and classification purposes, but also for the discovery of diagnostic and prognostic markers and the pathological mechanisms that drive tumorigenesis. The aim of this investigation was to confirm the presence and characterize the spatial distribution of the AMTN protein in benign OT, expecting that this expression profiling would provide additional insights into the modalities of OT formation.

\section{MATERIALS AND METHODS}

Paraffin blocks of cases of OT were retrieved from the archives of the Departments of Oral Pathology, Faculty of Dentistry, University of Toronto (UofT), Canada and the Federal University of Santa Catarina (UFSC), Brazil. Samples comprised 15 cases of ameloblastomas, one AF, two AFO, four odontomas, four AOT and three CCOT (Table 1). Two samples of a dental follicle containing reduced enamel epithelium were used as positive control. The use of all archival material in this study has been approved by the institutional research ethics board.

Table 1. Number of cases and classification of Odontogenic Tumors analyzed in the study according to WHO*.

\begin{tabular}{llc}
\hline Neoplasm & Classification according to WHO & $\begin{array}{c}\text { Number of samples } \\
\text { analyzed }\end{array}$ \\
\hline Ameloblastoma & $\begin{array}{l}\text { Odontogenic epithelium with mature stroma, } \\
\text { without odontogenic ectomesenchyme }\end{array}$ \\
Adenomatoid Odontogenic Tumor & \\
\hline Ameloblastic Fibroma & $\begin{array}{l}\text { Odontogenic epithelium with odontogenic } \\
\text { ectomesenchyme, with or without hard tissue } \\
\text { fmeloblastic Fibro-odontoma }\end{array}$ & $\begin{array}{l}2 \\
\text { Odontoma }\end{array}$ \\
Calcifying Odontogenic Cyst & & 4 \\
\hline
\end{tabular}

* Kramer et al. 1992; Barnes et al. 2005 


\section{Preparation of Rabbit Anti-Human Polyclonal Antibodies against AMTN}

Two peptides, derived from the human AMTN sequence, AMTN-1 (H2N-RLPTPSGTDDDFAVT$\mathrm{COOH}$ ) and AMTN-2 (H2N-PPTKLAPDQGTLPNQ$\mathrm{COOH}$ ), were synthesized and coupled to keyhole limpet hemocyanine (KLH) at the Advanced Protein Technology Centre, Hospital for Sick Children (Toronto, ON, Canada) and injected into white New Zealand rabbits for the production of polyclonal antisera according to a standard 112-day protocol (Harlan Bioproducts for Science, Indianapolis, IN, USA). The antisera were affinity purified over a primary $\mathrm{CNBr}$-activated sepharose $4 \mathrm{~B}$ column (GE HealthCare Bio-Sciences - Piscataway, NJ, USA) coupled to bovine serum albumin (BSA), a second CNBr-activated sepharose 4B column coupled to BSAAMTN-1 or BSA-AMTN-2 and eluted with $50 \mathrm{mM}$ Glycine- $\mathrm{HCl} / 0.5 \mathrm{M} \mathrm{NaCl}(\mathrm{pH} 2.3)$ according to a standard protocol [27]. Western blots and peptide competition assays were performed to confirm the specificity of binding to AMTN. Briefly, a whole cell protein lysate prepared from the human ameloblastoma cell line AM-1 [28] was spiked with 20ng of the recombinant human AMTN (rh-AMTN) protein, separated on a $12 \%$ polyacrylamide gel and transferred to a PVDF (Polyvinylidene Difluoride) membrane (Sigma Aldrich - St. Louis, MO, USA). Subsequently, membranes were blocked overnight at $4 \mathrm{C}$ with gentle shaking in Tris-Buffered Saline (TBS-T; $50 \mathrm{mM}$ Tris$\mathrm{HCl}, \quad 150 \mathrm{mM} \mathrm{NaCl}, \quad 0.1 \%$ Tween-20; $\mathrm{pH}$ 7.4) containing 5\% skim milk and probed with primary rabbit anti-AMTN-1 and anti-AMTN-2 antibodies at 1:500 for 30 minutes (both antibodies were diluted in the blocking solution cited above). The secondary goat anti-rabbit antibody (Cat. Nr. 172-1019, Bio-Rad Hercules, CA, USA) at 1:200000 dilution was applied for 1 hour at room temperature. After six washes of five minutes each with TBS-T at room temperature, signal was detected with Amersham's ECL detection kit (GE HealthCare Bio-Sciences - Piscataway, NJ, USA) according to the manufacturer's instructions. For peptide competition procedures, the human anti-AMTN antibodies were pre-incubated with respective antigenic peptides (human AMTN-1 or AMTN-2) or a nonrelated peptide (mouse Zfp60) for one hour at room temperature with gentle rocking, prior to their application in western blots. A 200 -fold molar excess of peptide was used.

\section{Immunohistochemistry}

A standard immunohistochemistry procedure was performed utilizing a commercially available kit (DakoCytomation, K4010, DAKO, Glostrup, Denmark). $5 \mu \mathrm{m}$ thick sections were cut from archival formalin-fixed, paraffin-embedded tissue samples and mounted on histological slides (Superfrost Plus, Fisher Scientific - Pittsburgh, PA, USA). Sections were deparaffinized in xylene and rehydrated in a series of graded ethanol dilutions. After brief washes in distilled water and $0.1 \%$ Tween 20 TBS-T $(50 \mathrm{mM}$ Tris- $\mathrm{HCl}$, $150 \mathrm{mM} \mathrm{NaCl}, \mathrm{pH}$ 7.4) (Sigma Aldrich - St. Louis, MO, USA), slides were incubated for 5 minutes at room temperature in peroxidase block solution to quench endogenous peroxidase. Sections were incubated for 30 minutes at room temperature with primary rabbit-anti-AMTN antibody diluted 1:1000 in $0.05 \mathrm{M}$ Tris- $\mathrm{HCl}$ with $1 \%$ BSA (Albumin fraction $\mathrm{V}$, Cat. Nr. A-3311, Sigma Aldrich, St. Louis, MO, USA). After five washes of three minutes each with TBS-T, the secondary antibody (Peroxidase Labelled Polymer) was applied for 30 minutes at room temperature. Staining was developed using diaminobenzidine hydrochloride (DAB) for 4 minutes and subsequent counterstain with Methyl Green for 30 seconds, followed by dehydration, mounting and analysis at a light microscope. For the negative control, the primary antibody was replaced by pre-immune serum from the respective rabbit (1:1000). Each tissue sample was tested with both anti-AMTN-1 and anti-AMTN-2 antibodies, revealing an identical pattern of immunohistochemical staining in terms of signal strength and localization.

\section{RESULTS}

The production and affinity purification of rabbit antiAMTN antisera yielded two valuable reagents with high specificity for bacterially expressed, recombinant human AMTN protein, which was recognized as a single band of the expected molecular weight $(24 \mathrm{kDa})$ by both anti-AMTN-1 (not shown) and anti-AMTN-2 antibodies (Figure 1, lane B). The rh-AMTN was also precisely identified within a complex protein mixture, a whole cell lysate from a human ameloblastoma cell line (Figure 1, lanes $\mathrm{C}$ and D). Peptide competition procedures further validated the specificity of the signal. The human anti-AMTN-2 antibody competed with either the antigenic AMTN-1 peptide or an unrelated peptide (Zfp60), properly recognized the recombinant human AMTN protein within the cell lysate (Figure 1, lanes E and G). On the other hand, when competed with the antigenic AMTN-2 peptide, no signal was observed (Figure 1, lane F). The human anti-AMTN-1 antibody presented similar results (not shown). A second, far less intense band at approximately $48 \mathrm{kDa}$ was detected by both antisera. Pre-immune rabbit sera did not produce any signal in these Western blots, or in any of the investigated tissue sections (not shown). 
Stolf et al.

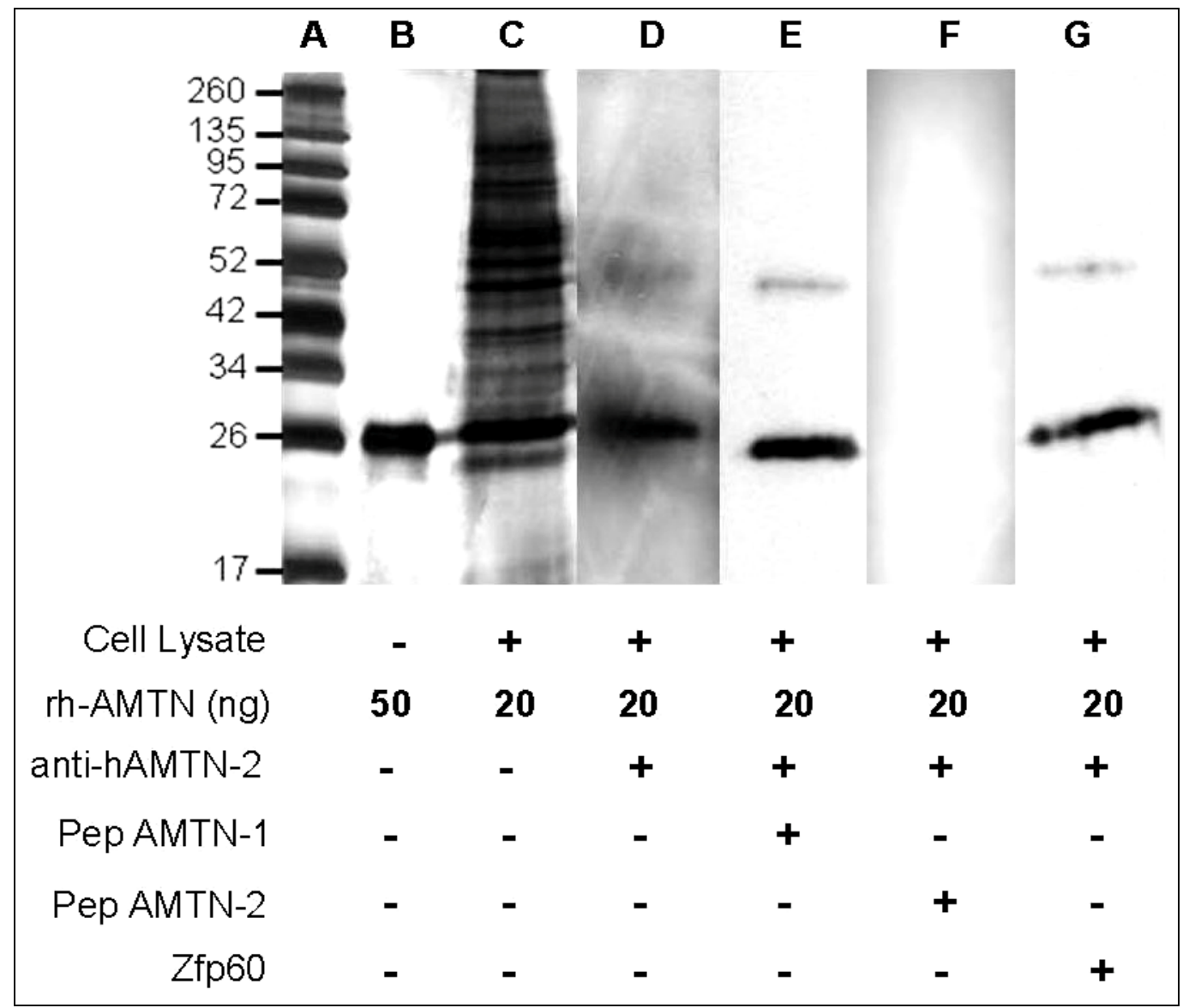

Figure 1. Validation of affinity purification procedure. A. Coomassie blue stained gel showing molecular weight protein marker. B. Silver stained gel showing pure recombinant human AMTN (rh-AMTN) protein. C. Silver stained gel of a whole cell protein lysate prepared from the human ameloblastoma cell line. The whole cell lysate, spiked with 20ng of the human recombinant AMTN protein $(\mathrm{Mw}=24 \mathrm{kDa})$ and probed with anti-AMTN-2 antibody, is shown in lane D. E, F and G. Peptide competition procedure. The whole cell protein lysate spiked with 20ng of rh-AMTN and probed with anti-AMTN-2 antibody has been competed with indicated peptides: E. Antigenic peptide AMTN-1; F. Antigenic peptide AMTN-2; G. Unrelated peptide Zfp60.

The immunohistochemical analysis of dental follicle sections, which was used as a positive control, revealed strong staining in the cytoplasm of the cells that constitute the reduced enamel epithelium. Sometimes, perinuclear and/or nuclear staining were also observed (Figure 2). These cells correspond to the ameloblasts in the final stages of enamel development, and this expression pattern is consistent with the profile of AMTN described for mouse and rat $[8,9]$.

Figures 3 and 4 show the immunolocalization of AMTN in all tumor samples tested. As adjacent sections were generally not available, a similar area from the tumor tissue was stained with hematoxylin and eosin (H\&E) to reveal morphological features for comparison.

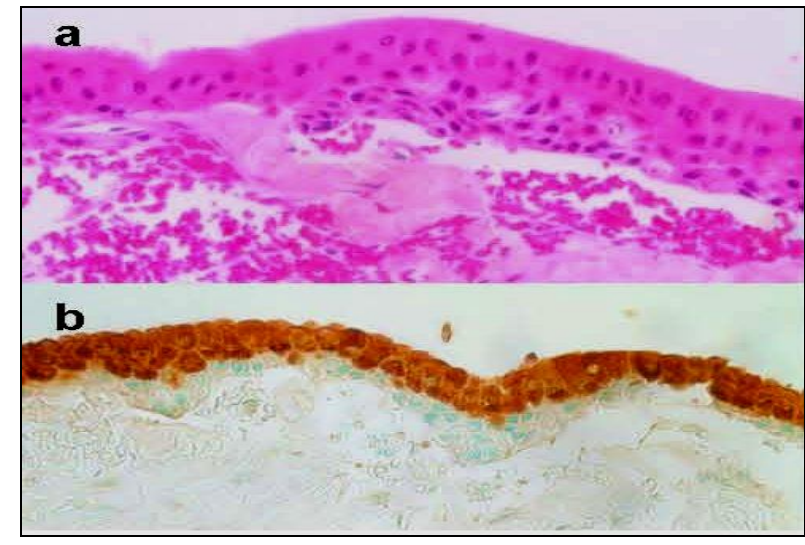

Figure 2. Immunohistochemical staining of AMTN in dental follicle used as positive control in this study. A: Normal dental follicle (H\&E, 40X); B: Positive immunohistochemical staining in reduced enamel epithelium that lines the dental follicle (Immunohistochemistry [IHC], 40X). 
Regarding the tumor samples, ameloblastomas were generally negative for AMTN. The central mass of loosely connected cells resembling the stellate reticulum did not present any signal; and the columnar cells that constitute the periphery of the tumor islands were also negative (Figure $3 \mathrm{~b}$ and $3 \mathrm{c}$ ). While the epithelial cells that constitute AOT showed negative staining, focal areas of the extracellular eosinophilic matrix revealed a strong signal for AMTN, with stronger staining in regions that have been reported to coincide with sites of tissue calcification (Figure $3 \mathrm{e}$ and 3f). Areas showing dentin-like formation did not present any signal.

The AF case was negative for AMTN (not shown). The two cases of AFO presented strong positive staining of the ameloblast-like columnar cells and the adjacent enamel matrix, while other cellular components of the tumor were negative (Figure $4 \mathrm{~b}$ and $4 \mathrm{c}$ ). Odontoma cases also showed an intense staining in the ameloblastlike layer and the patches of enamel matrix (Figure $4 \mathrm{e}$ and 4f), although the staining was not uniform in the latter, being more prominent in highly eosinophilic areas that have been reported to coincide with foci of calcification [24]. Interestingly, ghost cells within odontomas were variably positive for AMTN, with stronger staining in areas that have been reported as sites of dystrophic calcification (Figure 4k). A great number of positively stained ghost cells were also found in the CCOT sections, with labeling varying in strength (Figure $4 \mathrm{~h}$ and $4 \mathrm{i}$ )

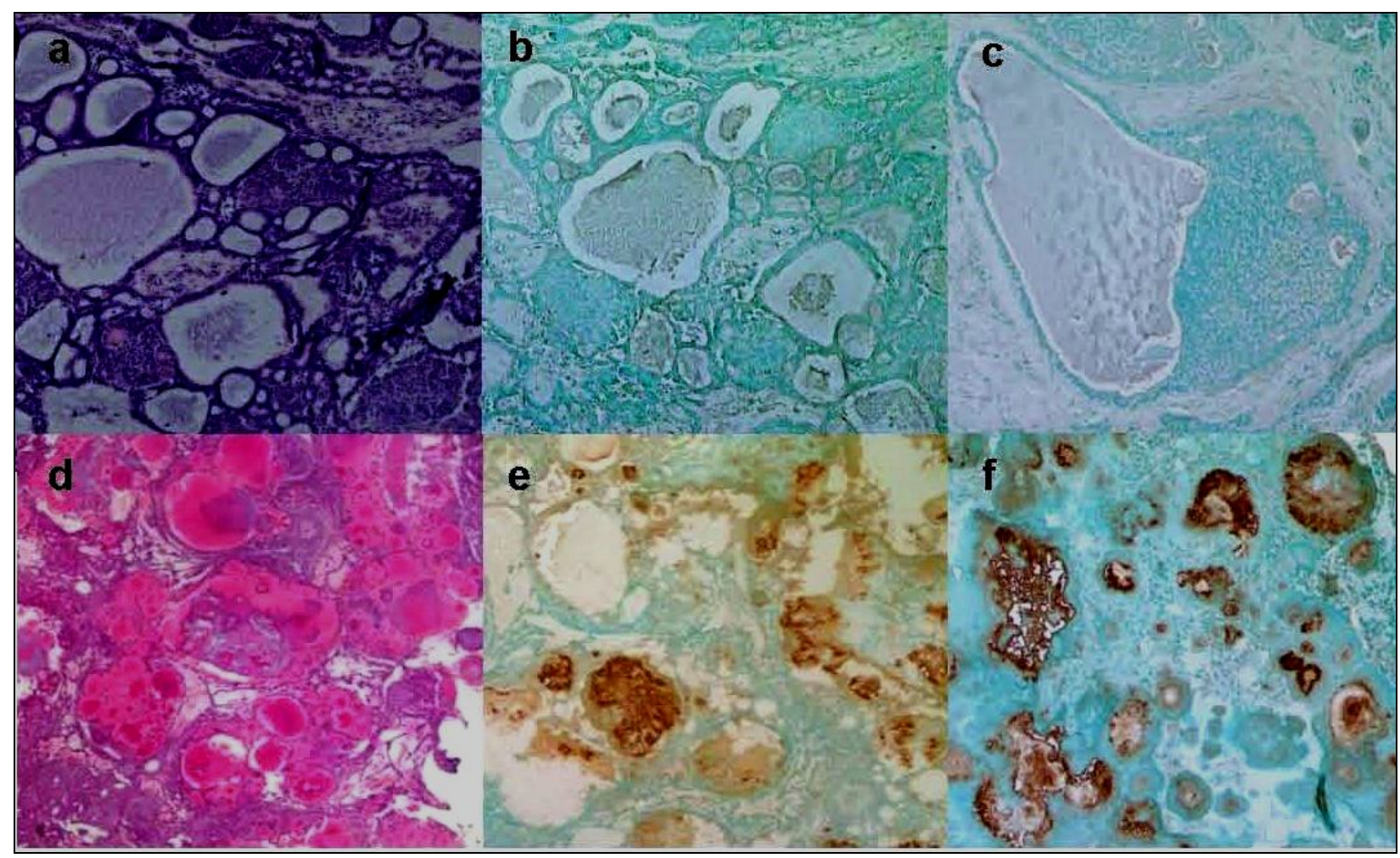

Figure 3. Immunohistochemical results for odontogenic tumors from epithelial origin. No AMTN expression was found in the ameloblastoma samples tested (A: H\&E, 20X; B and C: IHC [AMTN], 20X). Tumor droplets of adenomatoid odontogenic tumors presented a strong staining (D: H\&E, 20X; E and F: IHC [AMTN], 40x). 


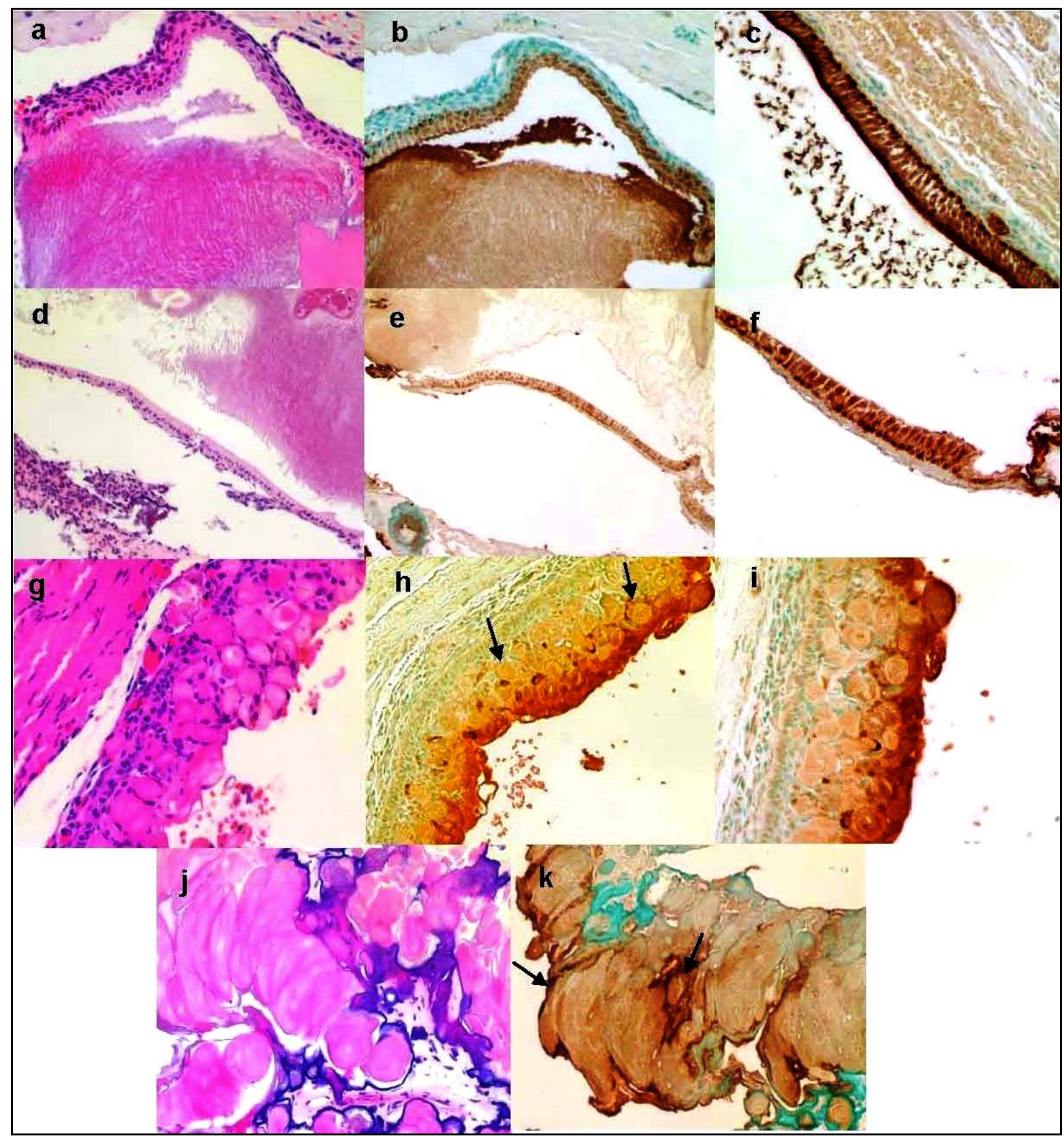

Figure 4. H\&E staining and immunohistochemistry results for odontogenic tumors from mixed origin. Note the variable staining found in ghost cells in Odontoma and CCOT samples (arrows). Ameloblastic Fibro-Odontoma (A: H\&E, 20X; B: IHC, 20X; C: IHC, 40X), Odontoma (ameloblasts) (D: H\&E, 10X; E: IHC, 10X; F: IHC, 40X), Calcifying Cystic Odontogenic Tumor (G: H\&E, 20X; H: IHC, 20X; I: IHC, 40X), Odontoma (ghost cells) (J:H\&E, 20X; K: IHC, 20X).

\section{DISCUSSION}

We have developed two useful antisera against the human amelotin protein and used them to study the spatial distribution of AMTN in odontogenic tumors by immunohistochemical detection. Western blots and peptide competition assays were used to validate the specificity of the antibodies developed. Bands of the expected size were observed in all immunoblots performed. It may be speculated that the less intense band detected at approximately $48 \mathrm{kD}$ might be a dimer, as regards to its size. However, it is not yet clear by what means such bonds are formed. Another possibility 
is that it might represent the result of a transglutaminase-mediated cross-link, presenting high resistance to proteolytic degradation. Further studies should clarify this query.

Generally, ameloblastomas did not demonstrate evidence of AMTN staining. Previous immunohistochemical studies of ameloblastomas have failed to detect amelogenin, the major protein component of enamel matrix, in tumor cells, even though mRNA expression analysis by RT-PCR in combination with Northern Blot and in situ hybridization have clearly demonstrated evidence of amelogenin mRNA expression [7, 21, 29, 30]. Thus, it was suggested that mutations in the expressed mRNA may interfere with the normal translational process leading to a functional protein [7]. Similar results were obtained for enamelin and sheathlin, since these proteins could not be immunolocalized in human ameloblastoma tissue samples [21, 23].

While ameloblastomas partly resemble the enamel organ, no enamel formation is observed in the structural organization of the tumor. Apparently, the tumor cells do not reach their fully differentiated state and this may be the reason for the absence of matrix formation [7]. The data obtained in this study supports the evidence that lack of inductive changes prevent the differentiation of the ameloblast-like cells, since they do not produce the AMTN protein that is characteristic of ameloblasts.

AFO and odontoma are considered hamartomas or developmental malformations. They show evidence of inductive changes in the odontogenic epithelium and ectomesenchyme. Previous studies have demonstrated the expression of amelogenin, sheathlin and MMP-20 in the ameloblast-like cells of AFO, supporting the idea that these tumor cells have undergone ameloblastic differentiation $[23,24,26]$. These proteins have also been identified in areas mimicking the dental enamel in both AFO and odontomas, suggesting that the matrix present in these lesions is immature since fully mineralized or mature enamel would normally lack such proteins $[23-25,31]$. We observed strong AMTN staining in ameloblast-like cells adjacent to the enamel matrix in these tumors, which is analogous to the expression of AMTN in the maturation stage of enamel formation in the developing tooth. This data indicate that the process of maturation has at least been initiated, and imply that some level of differentiation may be occurring in those cells.

Expression of amelogenin, enamelin and sheathlin has also been described in AOT. The first two proteins were found mainly in small mineralized foci, in the cytoplasm of cells forming epithelial nests and in hyaline droplets $[21,22,25]$. Sheathlin, on the other hand, was immunolocalized to the eosinophilic substance found in tumor cell nests, thought to be either basement-membrane like material [32] or abortive enamel matrix [20,21], and also in the cytoplasm of surrounding cells. Conversely, tumor cells forming the duct-like structures were negative, suggesting absence of maturation into secretory ameloblasts [23]. MMP-20 was also found to be expressed in the extracellular deposits of AOT. Small hyaline droplets and the majority of calcified areas showed strong immunoreaction for this proteinase [24].

The staining pattern observed for AMTN in AOT was similar to those reported above. The eosinophilic matrix and small mineralized foci were labeled. A very faint staining could be observed in the cytoplasm of some epithelial cells neighboring those areas. The fact that these cells do not present a strong reaction for AMTN, although the protein is localized to the mineralized structures around them, may indicate that the cells actually have reached the end of maturation stage. Earlier studies suggested that AOT may arise from the reduced enamel epithelium and that the tumor cells correspond to ameloblasts in the protective stage of odontogenesis. This suggestion was supported by the finding of a strong CK14 immunoreaction in all tumor cells of AOT, including the duct-like structures [33]. Additionally, given the co-existence of amelogenin, enamelin, sheathlin and AMTN in mineralized areas of the tumor, one may hypothesize that MMP-20 and KLK4 activity is compromised, and thus fails to fully degrade the first three proteins.

Alternatively, a deregulated early and rapid secretion of AMTN may also be hypothesized, since high expression of this protein is found in the mineralized foci that mimic the dental enamel, which is not seen in normal development [9]. Thus, a disorganized sequence of matrix secretion and mineralization may be occurring in these odontogenic tumors.

Ghost cells are a distinctive feature of CCOT, but are also found in other odontogenic and non-odontogenic lesions, such as odontomas and craniopharyngiomas, respectively. These cells often undergo dystrophic calcification [34-39]. Some authors have described ghost cells as derivatives from odontogenic epithelium that have undergone metaplastic change and show aberrant keratin formation [34]. Other authors suggested that the appearance of ghost cells may be the result of unsuccessful enamel matrix production in odontogenic epithelium [40]. Defective enamel-like matrix could be retained within the cells due to inability to secrete [41]. Ultrastructurally, ghost cells are characterized by the presence of coarse bundles of tonofilaments and loss of nuclei [42,43]. Another possible explanation for the appearance of these cells is related to coagulative necrosis of the odontogenic 
epithelium [43].

Strong staining of ghost cells for amelogenin, enamelin and sheathlin have been reported in the literature [20, $21,23,25]$. Three cases of CCOT associated with odontomas and presenting enamel matrix also expressed sheathlin intensely. The authors proposed that the abnormal accretion of such enamel proteins may be responsible for the appearance of ghost cells in this lesion [23]. As expected, MMP-20 was also found to be strongly expressed in CCOT. Variable staining in ghost cells, mainly in peripheral areas of the clusters was revealed, as well as in the immature enamel observed in some cases [24].

We observed staining for AMTN in ghost cells in both CCOT and odontoma, consistent with the proposal that abnormal accretion of enamel proteins may be responsible for the appearance of ghost cells [23]. The intensity of AMTN staining varies and is more intense in areas of calcification, indicating that the protein may be related to mineralization events. Although further studies are needed to demonstrate this hypothesis, a recent investigation where AMTN was both transgenically overexpressed and produced at an earlier stage during amelogenesis indicated that the protein plays a significant role in the structural properties of enamel and in the instruction of the matrix that directs mineralization [44].

In conclusion, the AMTN protein can be detected by immunohistochemical staining in ameloblast-like cells and the adjacent enamel matrix in AFO and odontoma. In these two odontogenic tumors that are considered hamartomas, AMTN expression correlates with differentiation of ameloblasts and maturation of enamel matrix. The absence of AMTN staining in the tumor cells of ameloblastoma suggests that the ameloblastlike cells in this tumor are not mature enough to produce AMTN, which is associated with enamel matrix production. Staining of ghost cells for AMTN is observed and is particularly strong in areas of calcification.

Taken together, these results support the idea from earlier studies of a possible involvement of the AMTN protein in mineralization events that occur at the final stages of enamel formation. Additional investigations should elucidate whether AMTN expression in odontogenic tumors can be used as a marker of tumor cell differentiation and/or maturation and mineralization of enamel-like matrix.

\section{ACKNOWLEDGMENTS}

We are grateful to Dr. José Nazareno Gil, Dr. Elena Riet Correa Rivero and Dr. Filipe Modolo for their assistance in the collection of ameloblastoma cases from the archives of the Department of Oral Pathology, Faculty of Dentistry, Federal University of Santa Catarina (UFSC) - Brazil; to Maise Tung, from the Department of Oral Pathology, Faculty of Dentistry, University of Toronto - Canada, for technical assistance; and to Dr. Takeshi Mitsuyasu, from the First Department of Oral and Maxillofacial Surgery, Faculty of Dentistry, Kyushu University - Japan, for kindly providing the human ameloblastoma cell line AM-1. This work was supported by a grant (MOP-79449) from the Canadian Institutes of Health Research (CIHR).

\section{REFERENCES}

1. Avery JK. Essentials of oral histology and embryology a clinical approach. Mosby, St. Louis, United States, pp 53-70, 1992.

2. Maas R, Bei M. The genetic control of early tooth development. Crit Rev Oral Biol Med 1997; 8:4-39.

3. Miletich I, Sharpe PT. Normal and abnormal dental development. Hum Mol Genet 2003; 12:R69-73.

4. Nanci A. Enamel: composition, formation, and structure. In: Dolan JJ (ed) Ten Cate's Oral Histology: development, structure, and function. Mosby, St. Louis, United States, pp 141-190, 2008.

5. Thesleff I, Sharpe P. Signaling networks regulating dental development. Mech Dev 1997; 67:111-123.

6. Eversole LR, Wysocki GW, Sapp P. Contemporary Oral and Maxillofacial Pathology. Mosby, St. Louis, United States, pp 135-143, 2004.

7. Tsujigiwa H, Nagatsuka H, Han PP, Gunduz M, Siar CH, Oida S, Nagai N. Analysis of amelogenin gene (AMGX, AMGY) expression in ameloblastoma. Oral Oncol 2005; 41:843-850.

8. Iwasaki K, Bajenova E, Somogyi-Ganss E, Miller M, Nguyen V, Nourkeyhani H, Gao Y, Wendel M, Ganss B. Amelotin - a novel secreted, ameloblast specific protein. J Dent Res 2005; 84:1127-1132.

9. Moffatt P, Smith CE, St-Arnaud R, Simmons D, Wright JT, Nanci A. Cloning of rat amelotin and localization of the protein to the basal lamina of maturation stage ameloblasts and junctional epithelium. Biochem J 2006; 399:37-46.

10. Kramer IRH, Pindborg JJ, Shear M. Histological typing of odontogenic tumors. Springer-Verlag, Berlin, Germany, pp 1-124, 1992.

11. Barnes L, Eveson JW, Reichart P, Sidransky D. Pathology and Genetics of Head and Neck Tumours. In: Kleihues R Sobin LH (series eds) World Health Organization classification of tumours, pathology and genetics of head and neck tumours. World Health Organization - IARC Press, Lyon, France, pp 296-318, 2005.

12. Altini M, Farman AG. The calcifying odontogenic cyst. 
Eight new cases and a review of the literature. Oral Surg Oral Med Oral Pathol 1975; 40:751.

13. Praetorius F, Hjorting-Hansen E, Gorlin RJ, Vickers RA. Calcifying odontogenic cyst: Range, variations and neoplastic potential. Acta Odontol Scand 1981; 39:227240 .

14. Ikemura K, Horie A, Tashiro H, Nandate M. Simultaneous occurrence of calcifying odontogenic cyst and its malignant transformation. Cancer 1985; 56:28612864.

15. Grodjesk JE, Dolinsky HB, Schneider LC, Dolinsky EH, Doyle JL. Odontogenic ghost cell carcinoma. Oral Surg Oral Med Oral Pathol 1987; 63:576-581.

16. Castle JT, Arendt DM. Aggressive (malignant) epithelial odontogenic ghost cell tumor. Ann Diagn Pathol 1999; $3: 243-248$

17. Chen Y, Li TJ, Gao Y, Yu SF. Ameloblastic fibroma and related lesions: a clinicopathologic study with reference to their nature and interrelationship. J Oral Pathol Med 2005; 34:588-595.

18. Chen Y, Wang JM, Li TJ. Ameloblastic fibroma: a review of published studies with special reference to its nature and biological behavior. Oral Oncol 2007; 43:960969.

19. Sahoo S, Alatassi H, Bernstein M, Slone SP, Chagpar AB. Breast carcinoma metastatic to ameloblastoma: a unique tumour-to-tumour metastasis. Histopathology 2007; 50:815-817.

20. Mori M, Yamada K, Kasai T, Yamada T, Shimokawa H, Sasaki S. Immunohistochemical expression of amelogenins in odontogenic epithelial tumors and cysts. Virchows Arch A Pathol Anat Histopathol 1991; 418:319-325.

21. Saku T, Okabe H, Shimikawa H. Immunohistochemical demonstration of enamel proteins in odontogenic tumors. J Oral Pathol Med 1992; 21:113-9.

22. Murata M, Cheng J, Horino K, Hara K, Shimokawa H, Saku T. Enamel proteins and extracellular matrix molecules are co-localized in the pseudocystic stromal space of adenomatoid odontogenic tumor. J Oral Pathol Med 2000; 29:483-90.

23. Takata T, Zhao M, Uchida T, Kudo Y, Sato S, Nikai H. Immunohistochemical demonstration of an enamel sheath protein, sheathlin, in odontogenic tumors. Virchows Arch 2000; 436:324-329.

24. Takata T, Zhao M, Uchida T, Wang T, Aoki T, Barlett JD, Nikai H. Immunohistochemical detection and distribution of Enamelysin (MMP-20) in human odontogenic tumors. J Dent Res 2000; 79:1608-1613.

25. Abiko Y, Murata M, Ito Y, Taira T, Nishimura M, Arisue $\mathrm{M}$, Inoue $\mathrm{T}$, Shimono $\mathrm{M}$, Kuboki $\mathrm{Y}$, Kaku $\mathrm{T}$. Immunohistochemical localization of amelogenin in human odontogenic tumors, using a polyclonal antibody against bovine amelogenin. Med Electron Microsc 2001; 34:185-189.
26. Yagishita H, Taya Y, Kanri Y, Matsuo A, Nonaka H, Fujita H, Aoba T. The secretion of amelogenins is associated with the induction of enamel and dentinoid in an ameloblastic fibro-odontoma. J Oral Pathol Med 2001; 30:499-503.

27. Wilchek M, Miron T, Kohn J. Affinity chromatography. Methods Enzymol 1984; 104:3-55.

28. Harada H, Mitsuyasu T, Nakamura N, Higuchi $Y$, Toyoshima K, Taniguchi A, Yasumoto S. Establishment of ameloblastoma cell line AM-1. J Oral Pathol Med 1998; 27:207-212.

29. Snead ML, Luo W, Hsu DD-J, Melrose RJ, Lau EC, Stenman G. Human ameloblastoma tumors express the amelogenin gene. Oral Surg Oral Med Oral Pathol 1992; 74:64-72.

30. Mendenhall WM, Werning JW, Fernandes R, Malyapa RS, Mendenhall NP. Ameloblastoma. Am J Clin Oncol 2007; 30:645-648

31. Väänänen A, Tjäderhane L, Eklund L, Heljasvaara R, Pihlajaniemi T, Herva R, Ding Y, Bartlett JD, Salo T. Expression of collagen XVIII and MMP-20 in developing teeth and odontogenic tumors. Matrix Biol 2004; 23:153161

32. Courtney RM, Kerr DA. The odontogenic adenomatoid tumor. A comprehensive study of twenty new cases. Oral Surg Oral Med Oral Pathol 1975; 39:424-435.

33. Crivelini MM, Araújo VC, Sousa SOM, Araújo NS. Cytokeratins in epithelia of odontogenic neoplasms. Oral Dis 2003; 9:1-6.

34. Sedano HO, Pindborg JJ. Ghost cell epithelium in odontomas. J Oral Pathol 1975; 4:27-30.

35. Kerebel B, Kerebel LM. Ghost cells in complex odontoma: a light microscopic and SEM study. Oral Surg Oral Med Oral Pathol 1985; 59:371-378.

36. Keszler A, Guglielmotti AMB. Calcifying odontogenic cyst associated with odontoma: report of two cases. J Oral Maxillofac Surg 1987; 45:457-459.

37. Hirshberg A, Kaplan I, Buchner A. Calcifying odontogenic cyst associated with odontoma: a possible separate entity (odontocalcifying odontogenic cyst). J Oral Maxillofac Surg 1994; 52:555-558.

38. Moleri AB, Moreira LC. Comparative morphology of 7 new cases of calcifying odontogenic cysts. Oral Maxillofac Surg 2002; 60:689-696.

39. Regezi JA. Odontogenic cysts, odontogenic tumors, fibroosseous, and giant cell lesions of the jaws. Mod Pathol 2002; 15:331-341.

40. David K, Buchner A. Calcifying odontogenic cysts with intracellular amyloid-like material. Oral Surg 1976; 41:758-764.

41. Freedman PD, Lumerman H, Gee JK. Calcifying odontogenic cyst: a review and analysis of seventy cases. Oral Surg Oral Med Oral Pathol 1975; 40:93-105.

42. Mascrès C, Donohue WB, Vauclair R. The calcifying 
Stolf et al.

odontogenic cyst: report of a case. J Oral Maxillofac Surg 1990; 48:319-322.

43. Hong SP, Ellis GL, Hartman KS. Calcifying odontogenic cyst - a review of ninety two cases with reevaluation of their nature as cysts or neoplasms, the nature of ghost cells, and subclassification. Oral Surg Oral Med Oral
Pathol 1991; 72:56-64.

44. Lacruz RS, Nakayama Y, Holcroft J, Nguyen V, Somogyi-Ganss E, Snead ML, White SN, Paine ML, Ganss B. Targeted overexpression of amelotin disrupts the microstructure of dental enamel. PloS One 2012; 7:111.

This is an open access article licensed under the terms of the Creative Commons Attribution Non-Commercial License which permits unrestricted, non-commercial use, distribution and reproduction in any medium, provided the work is properly cited. 